Literature Reviews

\title{
Work-Family Conflict: A Synthesis of the Research from Cross-National Perspective
}

\author{
Francis Annor \\ Department of Psychology, University of Cambridge, United Kingdom
}

Article history

Received: 21-04-2014

Revised: $18-06-2015$

Accepted: 14-10-2015

Email: francis.annor@cantab.net

\begin{abstract}
Changing demographic trends occurring in the work and family spheres have made combining work and family responsibilities an increasingly challenging task for employees in virtually every nation. However, previous studies on work-family conflict have focused predominantly on Western and developed nations, with little attention to the experience of work-family conflict across different national contexts. Only recently have studies begun to examine work-family conflict from cross-national perspective. This paper presents a review of cross-national studies on work-family conflict focusing on the influences of cultural, institutional and economic factors. Overall, the review suggests that existing cross-national research on work-family conflict is narrow in scope, with most studies focused mainly on identifying differences in prevalence of the phenomenon across national contexts. The paper outlines agenda for future research to increase understanding of contextual influences on the experience of work-family conflict.
\end{abstract}

Keywords: Cross-National, Work-Family, Culture, Institutions, Economic

\section{Introduction}

The phenomenon of work-family conflict has attracted enormous research attention over the past four decades particularly due to the increased participation of women in the workforce and the concomitant changes in work and family structures. Work-family conflict occurs when role pressures in the work role make it more difficult to participate in the family role or vice versa (Greenhaus and Beutell, 1985). In addition to establishing the bi-directionality of work-family conflict (work-to-family conflict is distinguished from familyto-work conflict), this stream of research has contributed to our understanding of the antecedents and outcomes of work-family conflict (Byron, 2005; Eby et al., 2005; Michel et al., 2011). However, much of the research on work-family conflict has been conducted in Western and developed countries. Consequently, researchers have raised concerns about the extent to which knowledge on work-family conflict may be applied in non-Western contexts (Shaffer et al., 2011; Westman, 2005; Yang, 2005).

Indeed, the notion that individuals' experiences of the work-family interface vary across national contexts has been repeatedly emphasized in the work-family literature. Westman (2005) notes that work and family systems operate within and are influenced by the specific cultural, institutional and economic contexts in which they are embedded. It is acknowledged that cultural, institutional and economic settings vary widely across countries (Joplin et al., 2003). As such, awareness of the influence of national context is essential for a nuanced understanding of workers' experiences of juggling work and family responsibilities (OllierMalaterre et al., 2013). As noted by Powell et al. (2009), cultural assumptions underpin most of the concepts in the work and family literature such as conflict, role demands and gender roles. Moreover, government policies and prevailing economic conditions shape organizations' responses to work family issues and influence individuals' needs and expectations (Ollier-Malaterre et al., 2013).

However, a major weakness in the work-family research field is that although scholars often emphasize the importance of cross-national research, relatively few studies examine work and family issues from crossnational perspective. This weakness is evident in various meta-analyses on the work-family interface, none of which included national context as a possible antecedent or moderator (e.g., Byron, 2005; Eby et al., 2005; Michel et al., 2011). This paper contributes to the 
literature by synthesizing research on national level factors that shape individuals' experiences of the workfamily interface. Specifically, the paper reviews extant research on the influences of cultural, institutional and macroeconomic variables on individuals' experiences of work-family interface. Previous reviews on contextual influences on work-family conflict have focused mainly on cultural and, to some extent, institutional factors (Aycan, 2008; Ollier-Malaterre et al., 2013; Powell et al., 2009). First, drawing on existing cultural frameworks (e.g., Hofstede, 1980; House et al., 2004) the paper discusses the influence of cultural values and expectations on work-family interactions. Next, the paper discusses the impact of institutional factors, focusing on the roles of national level family policies and working time regulations in shaping experiences of the work-family interface. This is followed by a review of economic factors such as national wealth (affluence) and national level unemployment that may impact on individuals' experiences of reconciling work and family responsibilities. The paper concludes by suggesting directions for future research.

\section{Cultural Influences}

For the most part, previous research has relied on differences in cultural values and beliefs in explaining variations in work-family experiences across countries. Culture has been defined in different ways in the literature. According to Hofstede (1980, p. 9), culture refers to "the collective programming of the human mind that distinguishes the members of one human group from those of another". House and Javidan (2004, p. 16) also defined culture as "shared motives, values, beliefs, identities and interpretations or meanings of significant events that result from common experiences of members of collectives that are transmitted across generations". Common to these definitions of culture is the emphasis on shared values, behaviours and beliefs. Among a wealth of cultural dimensions identified in the literature, four have been considered relevant to explaining variations in workfamily conflict across countries (Powell et al., 2009). These include individualism- collectivism, gender egalitarianism, humane orientation and specificitydiffusion. To date, the individualism-collectivism and, to some extent, gender egalitarianism dimensions have received more attention among scholars studying workfamily issues (Ollier-Malaterre et al., 2013).

\section{Individualism-Collectivism}

The individualism-collectivism dimension has been applied to explain how work and family relationships are constructed in different contexts. Schein (1984) posits that there are variations in the extent to which individuals in different cultures separate work from family life. Segmentation between work and family roles is considered most common in individualistic societies, whereas integration of work and family life is most typical among collectivists (Schein, 1984). Perceptions of role segmentation and integration create varying opportunities for the experience of work-family conflict across different cultural contexts. Ashforth et al. (2000) argued that role segmentation decreases blurring between roles, making transitions between domains more difficult, whereas role integration increases blurring between roles and thus eases between-role transition. Moreover, Yang et al. (2000) argued that in individualistic societies sacrificing family time for work could be regarded as neglect of the family in pursuit of personal achievements, whereas in collectivistic cultures work is regarded as a means to support the family and less value is placed on personal and family time. Hence, sacrificing family time for work may be regarded as a short-term cost for the long-term welfare of the family.

In addition, the nature of demands encountered in the work and family domains as well as the resources available in these domains in collectivistic cultures may be different from those in individualistic cultures. Hofstede et al. (2010) noted that in collectivistic societies, individuals are expected to maintain harmonious relationships with extended family members such as in-laws and elderly relatives. As such, family obligations in most collectivistic societies often extend beyond responsibilities toward one's own children and spouse; individuals often have financial and emotional obligations towards extended family relations (Powell et al., 2009). Thus, extended family obligations may detract from time and energy resources of employed parents in collectivistic societies. Comparatively, extended family obligations, if any, may be less demanding in individualistic cultures since greater emphasis is placed on nuclear family relationships in these cultures. However, family relationships in collectivistic societies are also characterized by a high sense of reciprocity. Just as extended family relatives may pose additional demands on individuals, they also serve as important source of support (Powell et al., 2009). By contrast, in individualistic societies, this type of support is not often available or preferred (Aycan, 2008).

The strong family ties in collectivistic societies also find expression in human resource management practices in organizations. Relationships between employers and employees in collectivistic cultures are often conceived in moral terms "with mutual obligations for protection in exchange for loyalty" (Hofstede et al., 2010). This contrasts with individualistic cultures, where the relationship between employers and employees are typically conceived in transactional terms (Gelfand et al., 2004; Hofstede et al., 2010). Consequently, organizational practices such as selection, appraisal, reward and dismissal in collectivistic cultures are heavily 
influenced by individuals' relationship with members in the organization (Gelfand et al., 2004). This form of relationship may serve as indirect support from supervisors to subordinates in collectivistic cultures, which may minimize work demands on employees (Powell et al., 2009). In contrast, this form of support may not be available in individualistic cultures, as 'family-like' relationships at work may be deemed undesirable (Powell et al., 2009). However, to the extent that performance may not be directly linked to rewards in collectivistic cultures, cultivating healthy interpersonal relationships with people in superior positions at work is essential to gaining favours from them and this may constitute additional demands on employees.

\section{Gender Egalitarianism}

Defined as "the degree to which an organization or a society minimizes gender role differences while promoting gender equality" (House and Javidan, 2004, p. 12), gender egalitarianism reflects societal norms about the allocation of roles between men and women. In less gender egalitarian cultures there are greater distinctions in expected roles of men and women. Specifically, men are expected to value objective material success and to prioritize work over family, whereas women are expected to be more focused on the subjective quality of life and to prioritize family over work (Emrich et al., 2004). In contrast, societies with greater gender egalitarianism make less of a differentiation between women and men's social roles; both men and women are expected to participate in paid employment and share in housework (Emrich et al., 2004).

The varying beliefs and expectations regarding the roles of females and males impact on their relative positions in private and public realms in society (McDaniel, 2008). Egalitarian gender values have been linked with decreased inequalities in division of housework between women and men. Although women continue to bear a greater share of housework (Bianchi et al., 2012; Ruppanner, 2010), men's participation in these activities is significantly higher in cultures that place less emphasis on the breadwinner role (Thebaud, 2010). Thus, societies' level of gender egalitarianism appears to impact on the relative demands shouldered by men and women. Additionally, egalitarian gender values have been linked with favourable attitudes towards female participation in paid employment (Treas and Widmer, 2000). As suggested by Uunk et al. (2005), countries higher on gender egalitarianism are characterized by higher proportion of women in paid employment. Moreover, women in societies that emphasize egalitarian gender values are more likely to occupy positions of high authority, and thus may have significant influence on policies that support employees' need to combine work and family demands (Lyness and Kropf, 2005) Uunk et al. (2005) reported that in countries that promote gender equality, employers tend to be more supportive of employees' need to combine work and family life.

Since gender egalitarianism concerns distinctions in gender roles (Lyness and Judiesch, 2008), it may have implications for gender differences in experiences of the work-family interface in different cultural contexts. Drawing on Greenhaus and Beutell's (1985) notion that higher levels of involvement in one role makes it difficult to meet demands in another role, Powell et al. (2009) proposed that gender differences in work-family conflict may be more pronounced in low gender egalitarian cultures, where greater emphasis is placed on traditional gender roles. In contrast, gender differences in work-family conflict may be lower in higher gender egalitarian cultures, because of the overlapping roles of men and women.

\section{Review of Cross-Cultural Studies on Work-Family Conflict}

According to Powell et al. (2009), studies that have investigated cultural differences in work-family conflict could be classified into culture-as-referent and cultureas-dimensions studies. Culture-as-referent studies draw on the concept of culture in making predictions about work-family issues in one nation but do not measure culture or make cross-cultural comparisons (e.g., Aryee et al., 1999). While such studies may provide in-depth insight into the work-family interface within a specific cultural context, they do not explain the potential impact of culture on workfamily experience (Powell et al., 2009). In contrast, cultureas-dimensions studies refer to notions of culture or measure specific cultural dimensions in making comparisons of the work-family interface across different countries. This paper focuses on culture-as-dimensions studies, because such studies offer greater insight into the impact of cultural dimensions on work-family issues.

A growing number of studies examine prevalence of work-family conflict, with findings suggesting significant variations in levels of work-family conflict across different cultural contexts. Yang (2005) compared independent samples of employees in China and the US on a measure of overall work-family conflict and found that work-family conflict was significantly higher among employees in the US than employees in China. She interpreted this finding as supporting her hypothesis that work-family conflict tends to be higher in individualistic cultures than in collectivistic cultures. Yang based her prediction on the notion that work and family roles are viewed as compatible in collectivistic cultures. In contrast to Yang's study, Lu et al. (2010) compared levels of work-family conflict among British and Taiwanese employees and found that both men and women in Taiwan reported higher levels of work-tofamily conflict and family-to-work conflict than their counterparts in Britain. Similarly, Spector et al. (2007) 
analysed data from 20 countries that were placed in four country clusters, one of which was considered individualistic (Anglo) and the other three were considered collectivistic (Asia, East Europe and Latin America). Spector et al. (2007) found that time-based work-to-family conflict was slightly higher in Anglo countries than Asian countries, while strain-based workto-family conflict was significantly higher among Anglos than Asians and Latin Americans. The higher levels of conflict reported by employees in the Anglo cluster could be due to their relatively high levels of workloads compared to employees in other clusters.

While many cross-cultural studies do not explicitly test gender differences in work-family conflict, the few that do seem to support Powell et al.'s (2009) proposition that gender differences in work-family experiences are more pronounced in less gender egalitarian cultures than in high gender egalitarian cultures. Using data from the 2005 International Social Survey Program (ISSP), Ruppanner and Huffman (2013) examined the impact of gender empowerment (similar to gender egalitarianism) on work-family conflict in 31 countries. Gender empowerment was associated with decreased likelihood of family-to-work conflict among mothers, but had the opposite effect on family-to-work conflict for fathers. Interestingly, gender empowerment was associated with increased likelihood of work-tofamily conflict for both mothers and fathers. Lyness and Judiesch (2014) examined the influence of gender egalitarianism on gender differences in work-life balance among managers in 36 countries. The researchers captured gender egalitarianism with four different measures and used multisource data for work-life balance comprising self-reports and supervisor appraisals. Multilevel analysis showed small, albeit significant moderating effects of gender egalitarianism on gender differences in self-reported work-life balance. Specifically, women reported lower work-life balance than men in low gender egalitarian cultures. Gender differences in self-reported work-life balance in low gender egalitarian cultures were strongly linked to objective gender inequalities. Interestingly, gender egalitarianism had stronger influence on supervisors' ratings of managers' work-life balance. In low egalitarian countries supervisor ratings of female managers' work-family balance were significantly lower than their male counterparts. However, given that women may hold small proportion of managerial positions in low egalitarian cultures, supervisor ratings of female manager's work-life balance could be influenced by stereotypic beliefs about women.

In addition, another stream of research focuses on individualism-collectivism as a moderator in the relationships of work-family conflict with antecedent and outcome variables. These studies suggest that predictors of work-family conflict vary across different cultural contexts. For example, Yang et al. (2000) found that work demands were positively related to workfamily conflict for Chinese employees but were unrelated to work-family conflict for American employees. In contrast, Spector et al. (2007) found that higher work demands (work hours and perceived workload) were associated with higher levels of work-tofamily conflict among individualists than collectivists. The researchers suggested that individualists might view long working hours as taking away from the family, thereby leading to resentment and conflict in the family domain. Conversely, this may not be the case in most collectivistic societies where family members view long working hours as contribution to the family. Lu et al. (2010) also examined the relationships of work/family demands and support with work-to-family conflict in a cross-cultural study of British and Taiwanese employees. The researchers found supervisor support was associated with significantly lower levels of work-to-family conflict for Taiwanese than for British employees, suggesting that supervisor support was more beneficial for the Taiwanese employees.

Studies have also investigated cultural context as a moderator in the relationship between work-family conflict and outcomes. Findings from this stream of research suggest that outcomes of work-family experiences are more pronounced in some cultural contexts than in others. Spector et al. (2007) found that the relationship between work-to-family conflict and job satisfaction was stronger in individualistic cultures (Anglo) than collectivistic cultures (Asia, Latin America and East Europe). Similarly, Wang et al. (2004) studied the moderating effects of culture in the relationship between work-family conflict and turnover intentions among American and Chinese employees. Focusing on individual level cultural orientations, the researchers assessed allocentrism and idiocentrism, which roughly correspond with collectivism and individualism respectively. The researchers found that work-to-family conflict was positively related to turnover intentions among American employees but was not related to turnover intentions among the Chinese. Wang et al. (2004) speculated that since China is a collectivistic country, Chinese employees would be more likely to emphasize long-term relationship via loyalty with their organization. The positive relationship between work-tofamily conflict and turnover intentions was significantly stronger among employees who scored high on idiocentrism. More recently, Galovan et al. (2010) compared samples of employees in the US and Singapore on outcomes of work-family conflict. They found that work-to-family conflict had a stronger negative relationship with job satisfaction and a stronger 
positive relationship with depression in the US than in Singapore. Conversely, family-to-work conflict had a stronger negative relationship with job satisfaction and stronger positive relationship with depression in Singapore than in the US.

\section{Institutional Influences}

Although cultural comparisons have dominated comparative research on work-family issues, crosscultural studies often ignore other dimensions on which countries that supposedly emphasize similar cultural values may vary. For example, although the UK and Sweden may be classified as individualistic (see Hofstede, 1980) the two countries emphasize different ideologies regarding state interventions in work-family issues (Esping-Andersen, 1999). Thus, while cultural values and expectations could influence individuals' responses towards participation in the work and family domains, constraints and resources within the wider institutional context could also shape the daily realities of combining responsibilities in both life domains. A burgeoning stream of research, therefore, focuses on the influences of institutional factors such as social policies, in particular family policies and working time regulations, in understanding the work-family interface across countries. This section will focus on the impact of national family policies and working time regulations on work and family participation experiences.

\section{Family Policies}

In response to increased emphasis on work and family issues, several countries have instituted policies aimed at facilitating employees' combining paid employment and household labour. Most prominent among these policies include legally protected family leaves such as maternity leave, paternity leave, parental leave and sick leave; family tax and cash benefits; and childcare services (Lewis, 2009). Countries vary not only in the strategies they adopt in supporting families but also in the levels of support they provide. The existence of such cross-national variations in family policies is broadly captured in various welfare-state regime typologies (Esping-Andersen, 1990; 1999; Korpi, 2000; Lewis, 1992).

Family policies at the national level influence workfamily support provisions by organizations and thus shape reconciliation of work and family responsibilities. Drawing on institutional theory (Ingram and Simons, 1995), it has been argued that extensive family policies is indicative of state commitment to work-family issues and may create normative and coercive pressures on organizations to provide work-family support (den Dulk et al., 2013; Lewis and Haas, 2005). Relevant to this argument is the concept of sense of entitlement (Lewis and Smithson, 2001), which denotes "a set of beliefs and feelings about rights and entitlements, or legitimate expectations, based on what is perceived to be fair and equitable (p. 1457)." Thus, national policies that are supportive of the integration of paid work and family life may enhance employees' sense of entitlement to support (Lewis and Smithson, 2001), which may in turn increase institutional pressures on employers to respond in ways that are perceived to be equitable (Lewis and Haas, 2005). In contrast, some scholars have argued that it is the absence, rather than the presence of well-developed state provisions that increases employers' motivation to adopt work-family policies (den Dulk, 2005; den Dulk et al., 2013). It is assumed that firms' decisions to introduce family policies are influenced by economic considerations, with employers being more likely to adopt family-friendly measures when these are expected to yield net benefit to the organization (Seeleib-Kaiser and Fleckenstein, 2009). While evidence exists for both arguments (e.g., Beham et al., 2014; den Dulk, 2005; den Dulk et al., 2013), overall, the adoption of work-family polices seem to be influenced by organizational characteristics. Public rather than private sector organizations and large rather than small organizations seem more likely to adopt work-family arrangements (den Dulk et al., 2012).

At the individual level, some studies have examined the impact of national family policies on gender relations in the labour market and the household. State policies that support reconciliation of work and family life have been linked with increase in women's employment and economic autonomy, particularly that of mothers (Hegewisch and Gornick, 2011). Although some scholars have argued that women's employment patterns are largely determined by life style preferences (e.g., Hakim, 2002), empirical evidence suggests that the availability of supportive family policies can facilitate women's continuous attachment to the labour market (e.g., Pettit and Hook, 2005). Supportive family policies also seem to reduce wage penalties associated with motherhood (Gornick and Meyers, 2003; Stier et al., 2001). Increase in women's economic activity has been linked with men's participation in unpaid work. This trend appears more evident in countries that have policies to encourage men's participation in domestic work (Hook, 2006). However, some scholars have emphasized the possibility that family policies could worsen women's labour market outcomes (e.g., Mandel and Semyonov, 2006), though these concerns appear to be related to policies that grant parents lengthy time outside of paid employment (Lewis, 2009). In addition to facilitating women's attachment to the labour market, national family policies can directly influence individuals' ability to integrate work and family life. This expectation builds on research that has linked expansive family policy provisions with higher quality of work tasks (job autonomy and involvement in decision making) and greater schedule control (e.g., Gallie, 2003; 
Lyness et al., 2012). Grönlund and Öun (2010) argued that by supporting individual autonomy, family policies help minimize the difficulties of juggling work and family responsibilities. However, to date, comparative research on the impact of family policies on employees' workfamily experiences has been limited. The few studies in that regard have focused mainly on country differences in prevalence of work-family conflict, with inconsistent and somewhat contradictory results.

Some studies conclude that extensive family policies facilitate work-family balance. For example, Crompton and Lyonette (2006) compared work-family conflict in five European countries (France, Norway, Finland, Portugal and Britain) and found that living in Finland and Norway (countries that provide extensive workfamily support) was associated with lower levels of work-family conflict than living in the other European countries. In contrast, other studies indicate that national level family policies are associated with greater difficulty with combining work and family demands (e.g., Cousins and Tang, 2004; Strandh and Nordenmark, 2006). Cousins and Tang (2004) examined experiences of balancing work and family responsibilities in three European countries that vary in family policy regime (Sweden, the UK and the Netherlands). Surprisingly, despite extensive public workfamily support in Sweden, a higher proportion of both men and women in Sweden reported work-family conflict compared to the other two countries.

A difficulty with such cross-national comparative studies is the assumption that similar policy configurations have similar effects across different countries. As noted by Sullivan et al. (2009), "different policies within the same country may be founded on different models of work and family life". Thus, even within the same country the objectives of different policies might sometimes conflict and might result in contradictory effects. Hence, additional insight could be gleaned from studies that focused on the impact of specific family policies. Relevant in this regard is a recent 10-country multilevel analysis by Ruppanner (2011) based on data from the 2002 ISSP. She found that mothers and fathers reported less family-to-work conflict in countries with more expansive family leave policies. Mothers also reported less work-to-family conflict in countries with more expansive family leave policies and longer school scheduling. Interestingly, longer school scheduling was associated with greater work-to-family conflict for nonmothers. She speculated that longer school scheduling might be indicative of long work hour culture.

More recently, Allen et al. (2014) investigated the impact of national paid leave policies on four dimensions of work-family conflict (time- and strain-based work-tofamily conflict, time- and strain-based family-to-work conflict) among married working parents across 12 industrialized countries. Drawing on data from the second Collaborative International Study of Managerial Stress, Allen et al. (2014) demonstrated that paid sick leave had small but significant negative relationship with both types of family-to-work conflict and strain-based work-to-family conflict, whereas paid parental and annual leaves were not associated with work-family conflict. The researchers further demonstrated that paid leave policies were more beneficial when employees' perception of organizational and supervisor support were higher than when they were lower. Together, these studies suggest that the positive impact of national level family policies on work-family experiences may be true for some specific policies but not others.

\section{Working Time Regulations}

The regulation of working time has been a key focus of social policy for much of the twentieth century particularly in industrialized countries. Work hour reduction policies emerged from a concern for safeguarding the health and safety of workers and to provide 'leisure' time outside paid work (McCann, 2004). The establishment of normal weekly hours remains the primary mechanism for limiting working time in many countries (Gornick and Heron, 2006; Lee et al., 2007), with the International Labour Organization's $40 \mathrm{~h}$ week limit being the most dominant weekly hour standard (normal weekly hours refers to "a threshold beyond which overtime becomes payable" (Gornick and Heron, 2006, p. 153)) (Lee et al., 2007). However, increasing emphasis on flexibility, spearheaded by part-time work and annualization arrangements, has resulted in increased diversification of working times (annualization involves averaging weekly work hours over a reference period of up to a year (McCann, 2004)) (Anxo and O'Reilly, 2000; McCann, 2004). Analyses of working time distributions suggest that national differences in working time largely reflect variations in the institutional frameworks for regulating working hours (Anxo, 2004; Lee et al., 2007). Anxo and O'Reilly (2000) note that regulations of working hours may involve universal application of statutory agreements or collective bargaining at industry and plant levels. Generally, distribution of working time tends to be broader in countries with limited working hour legislations and strongly decentralized collective bargaining (Anxo, 2004; Lee et al., 2007).

It is assumed that regulations limiting the number of weekly work hours can potentially increase the amount of time available for non-work activities (Sayer and Gornick, 2011) and thus enhance workers' ability to integrate work and family responsibilities. However, empirical evidence suggests that policies limiting working hours do not necessarily increase involvement in family-related activities. Sayer and Gornick (2011) proposed that parents in countries where long working hours dominate would devote less time to childcare 
activities compared with parents in countries with short employment hours. Based on time diary data from nine countries, the researchers found no support for the proposed association of childcare levels and national work hour cultures. Paradoxically, they found that childcare hours were lowest among mothers and fathers in France and Sweden -countries with short work hour cultures-and highest among mothers and fathers in Canada and Slovenia-countries with long work hour cultures.

Fagnani and Letablier (2004) concluded that mechanically reducing working hours through regulations might not be sufficient in enhancing employees' work-family balance. The researchers based their conclusion on analysis of the impact of the French $35 \mathrm{~h}$ workweek law on the daily life of employed parents with children under six. It was observed that the impact of the $35 \mathrm{~h}$ law on work-family balance largely depended on the organization of work. While the impact was perceived as positive for a large majority of parents with regular schedules, those with irregular and unpredictable schedules perceived no significant change in their family life, or that the impact was negative. These findings support Anxo's (2004) statement, "being able to fulfil care responsibilities and social activities is not just about how much time is available, it is also about when people are available" ( $p$. 199). Thus, reduction in working time could make fulfilling family-related tasks more difficult, if individuals have to accept working non-standard schedules.

Additionally, the organization of working time has significant implications for gender equality in paid employment and household labour. Evidence from European countries indicates that countries with reduced working hours have lower gaps between men and women's labour market participation (Figart and Mutari, 2000). Women's participation may in turn influence men's contribution to domestic work. Hook (2006), based on time-use data from 20 countries, reported that men's unpaid work time was positively correlated with women's employment. However, Hook's finding might not generalize to countries where part-time work accounts for considerable reduction in working hours. It has been argued that in countries where part-time work remains overwhelmingly feminized and of relatively poor quality, reducing working hours through part-time work may not only reinforce women's role as caregivers, but could also widen the gender gap in paid work (Gornick and Heron, 2006). In this vein, regulations that limit weekly working hours could have the unintended consequence of widening gender inequalities.

\section{Economic Influences}

Beyond cultural and institutional factors, the economic context may shape how individuals negotiate between work and family domains. There is evidence to suggest that macroeconomic conditions, particularly those related to income and employment, impact on the experiences of workers in the work and home environments. In the job stress literature, a number of studies have related levels of national wealth and unemployment rates to workers' feelings of job stress (e.g., Fenwick and Tausig, 1994; Frey and Stutzer, 2002). These studies suggest that in affluent countries and in countries with low unemployment rates workers are less likely to report job stress. Fenwick and Tausig (1994) argued that macroeconomic forces affect the structure of work roles and exposure to work stressors. In difficult economic conditions such as decline in economic growth or recessions, more employees experience stress as firms may be forced to reduce their labour force (Joplin et al., 2003). Economic decline may also force employees to tolerate poor working conditions such as heavy workloads, working unsocial hours and reductions in wages, due to lack of alternative jobs and decrease in workers' bargaining power (McGinnity and Russell, 2013). Furthermore, increasing levels of unemployment may heighten workers' perception of employment insecurity (Nolan et al., 2000), which can aggravate individuals' feelings of stress.

Not only does the economic context affect workers' exposure to stressful conditions, but it can also affect the level of resources available for reconciling paid work and family responsibilities. For example, it has been suggested that lower unemployment rate at the country level may encourage work-family initiatives by employers to increase labour supply from skilled workers (den Dulk et al., 2013). In a similar vein, it has been demonstrated that developed countries tend to have stronger economies, which result in higher average household income (Spector et al., 2004). Thus, providing basic family needs would be relatively easier. High economic security in this context could also make it possible for employees to have shorter workweeks (Lyness et al., 2012). By contrast, in countries where average household incomes are low providing family needs is relatively more difficult. Consequently, working longer hours for additional income would be more common. In line with these suggestions, Stier and LewisEpstein (2003) found evidence that level of economic development was associated with employees' working time preferences. Based on multilevel analysis of data on 27 countries from the 1997 ISSP, Stier and Lewis-Epstein (2003) reported that workers were more likely to prefer reduced work hours in countries with higher GNP per capita. From the preceding arguments, one could expect that reconciling work and family responsibilities would pose greater challenge to workers in developing countries than to those in economically advanced nations.

However, the few studies that examined economic influences on the work-family interface reported mixed findings. One study found that economic decline was associated with a modest increase in work-family conflict (McGinnity and Russell, 2013). In this study, 
McGinnity and Russell (2013) compared levels of workfamily conflict in 20 European countries in 2004 (period preceding the financial crisis) and 2010 (a year of slow economic growth and generally higher unemployment). They observed that in countries where unemployment rose during the period individuals reported a slight increase in work-family conflict. The modest rise in work-family conflict was attributed to increase in work pressure. In another study among dual-earner couples, Steiber (2009) reported contradictory findings on the impact of economic conditions on individuals' workfamily conflict. They found that couples reported higher levels of time-based and strain-based work-family conflict in countries with higher unemployment rates. Interestingly, high standard of living (measured by GNP per capita) was also associated with increased likelihood of reporting work-family conflict. Steiber's findings were based on multilevel analysis of data on 23 countries from the second wave of the European Social Survey (ESS). However, overall, the moderating effect of economic context was modest after controlling for individual level factors.

In an earlier study, Uunk et al. (2005) investigated changes in women's working hours over time by comparing women's levels of work involvement prior to first birth to their levels of involvement two years after birth using data from the European Community Household Panel for 13 EU countries. Their findings suggest that, among countries with equal levels of public childcare, mothers in more affluent countries were more likely to reduce working hours after childbirth. The authors interpreted this finding as supporting their argument that mothers in less affluent countries remain in paid employment out of economic necessity. However, the reduction in working hours among mothers in affluent countries would not necessarily suggest greater difficulty in reconciling work and family demands. The fact that the more affluent countries in this study tend to have greater prevalence of part-time work (cf. Steiber and Haas, 2012) suggests that the longitudinal child effects observed in more affluent countries could be explained by the availability of alternative employment options.

\section{Future Directions and Conclusion}

Cross-national research remains an emergent field in the work-family literature. Focusing on culture, institutions and economic conditions, this paper has highlighted various ways in which experiences of the work-family interface might differ across national contexts. Cultural values may influence individuals' construction of work and family roles, the priorities they attach to these roles and the nature and sources of demands and support mechanisms existing therein. As such, culture may account for variations in prevalence of work-family conflict as well as differences in antecedents and outcomes of work-family conflict in different national contexts. The institutional and economic contexts also seem to have significant influences on how much support individuals could expect and the preferences they make between paid work and family responsibilities.

A major issue in cross-national literature on workfamily conflict is the lack of uniformity in conceptualization of work-family conflict. Constructs such as "work-family balance", "work-life balance" and "work-non-work conflict" have been used to represent work-family conflict in the literature. This situation may be due to work-family research being approached from diverse academic perspectives including psychology, sociology, social policy and management. A consequence of this proliferation of constructs is that different measures are used across different studies. Even large-scale surveys such as ISSP and ESS use very different measures for work-family conflict. This phenomenon makes it difficult to meaningfully compare results from different studies. Thus, differences found across studies could be an artefact of variations in how work-family conflict was conceptualized and measured.

Cross-national research on work-family conflict is limited in scope. For example, research examining cultural influences has focused predominantly on the individual-collectivism and, to some extent, gender egalitarianism dimensions of culture. To date, no study has focused on other cultural dimensions such as specificity/diffusion and humane orientation. Specificity/diffusion reflects the extent to which individuals in a culture segment or integrate their public and private lives, with specific cultures emphasizing segmentation and diffuse cultures emphasizing role integration (Trompenaars and Hampden-Turner, 1998). Humane orientation refers to "the degree to which individuals in organizations or societies encourage and reward individuals for being fair, altruistic, friendly, generous and caring and kind to others" (House and Javidan, 2004, p. 12). Powell et al. (2009) have articulated a number of propositions regarding the influence of these cultural dimensions on the workfamily interface. Studies testing these propositions empirically would contribute significantly to understanding the work-family interface from a cross-cultural perspective. Similarly, research on institutional and economic influences has mainly focused on differences in levels of work-family conflict across countries. While this line of research is important for understanding the pervasiveness of the phenomenon in different contexts, it does little in highlighting whether similar factors underlie work-family conflict in different contexts. Previous reviews have identified several antecedents and outcomes of work-family conflict that are related to both the work and family domains. Future research needs to examine whether and how the relationships of these variables with work- 
family conflict differ across different institutional and macroeconomic contexts.

Furthermore, there is a lack of integration of research focusing on cultural, institutional and macroeconomic influences on work-family conflict. Most cross-national studies have focused on either cultural factors or institutional and economic factors. Ollier-Malaterre et al. (2013) suggested that cultural, institutional and macroeconomic variables may interact to influence individuals' experiences of the work-family interface. Integrating cultural, institutional and macroeconomic variables in cross-national work-family research would enhance our understanding of what underlie similarities and differences in work-family experiences and employee outcomes. This would require moving beyond the two-country comparisons commonly adopted in cross-national studies on work-family conflict. Researchers should consider collecting data from multiple countries that differ along various cultural dimensions, institutional policies and macroeconomic characteristics.

Finally, mirroring the trend in single-country studies (see Shaffer et al., 2011), the neglect of sub-Saharan Africa is even more evident in cross-national studies. To date, no study has explicitly compared work-family conflict in a country in sub-Sahara Africa with a Western industrialized country. The only international survey that included a single African country (South Africa) was the 2005 ISSP (see Ruppanner and Huffman, 2013). A consideration of the sub-Saharan African context in cross-national research on the work-family interface is imperative, given prevailing socio-economic circumstances in the sub-region, some of which may be unknown elsewhere in the developed world. For example, many societies in sub-Saharan Africa place high cultural premium on marriage and procreation. This phenomenon, coupled with rapidly aging populations and high prevalence of HIV/AIDs and other health pandemics (Aryee, 2005; Mokomane, 2012) contribute to an increasing need to provide care for young children and vulnerable relatives. In addition, the relegation of work-family issues to the private realm implies a general lack of family-friendly provisions from governments and organizations for reconciling work and family life in many countries in sub-Saharan Africa (Annor, 2014). Moreover, lack of adequate infrastructure such as reliable transport, electricity, water supply, healthcare systems and other basic amenities that characterize lowincome countries further increases demands on individuals' time and energy, especially among women. Therefore, future cross-national studies that include countries in sub-Saharan Africa would shed light on the extent to which work-family experiences in this unique socio-cultural context may be similar or different from Western and industrialized societies.

\section{Acknowledgements}

The author wishes to thank Dr Brendan Burchell (University of Cambridge) for his helpful comments on an earlier version of the manuscript.

\section{Funding Information}

The author received financial support from the Cambridge Commonwealth Trust and St John's College of the University of Cambridge while conducting this literature review.

\section{Author's Contributions}

This article is work of the author with no contribution from any other person.

\section{Ethics}

This article is original and contains unpublished material.

\section{References}

Allen, T.D., L.M. Lapierre, P.E. Spector, S.A. Poelmans and M. O'Driscoll et al., 2014. The link between national paid leave policy and work-family conflict among married working parents. Applied Psychol., 63: 5-28. DOI: 10.1111/apps.12004

Annor, F., 2014. Managing Work and Family Demands: The Perspectives of Employed Parents in Ghana. In: Work-Family Interface in Sub-Saharan Africa, Mokomane, Z. (Ed.), Springer International Publishing, ISBN-10: 978-3-319-01237-7, pp: 17-36.

Anxo, D., 2004. Working Time Patterns among Industrialized Countries: A Household Perspective. In: Working Time Preferences in Industrialized Countries: Finding the Balance, Messenger, C. (Ed.), Routledge, Abingdon, England, ISBN-10: 0415701082, pp: 60-107.

Anxo, D. and J. O'Reilly, 2000. Working-Time Regimes and Transitions in Comparative Perspective. In: Working-Time Changes: Social Integration through Transitional Labour Markets, O’Reilly, J., I. Cebrián and M. Lallement (Eds.), Edward Elgar Publishing, ISBN-10: 9781840642803, pp: 61-92.

Aryee, S., 2005. The work-family interface in urban subSaharan Africa: A theoretical analysis. In: Work and Family: an International Research Perspective, Work and Family: An International Research Perspective, Poelmans, S.A.Y. (Ed.), Lawrence Erlbaum Associates, Mahwah, ISBN-10: 0805848827, pp: 261-286.

Aryee, S., D. Fields and V. Luk, 1999. A cross-cultural test of a model of the work-family interface. J. Manage., 25: 491-512.

DOI: $10.1177 / 014920639902500402$ 
Ashforth, B.E., G.E. Kreiner and M. Fugate, 2000. All in a day's work: Boundaries and micro role transitions. Acad. Manage. Rev., 25: 472-491. DOI: $10.5465 / A M R .2000 .3363315$

Aycan, Z., 2008. Cross-Cultural Perspectives to WorkFamily Conflict. In: Handbook of Work-Family Integration: Research, Theory and Best Practices, Korabik, K., D. Lero and D.L. Whitehead (Eds.), Elsevier Inc., London, pp: 359-371.

Beham, B., S. Drobnič and P. Präg, 2014. The workfamily interface of service sector workers: A comparison of work resources and professional status across five European countries. Applied Psychol., 63: 29-61. DOI: 10.1111/apps.12012

Bianchi, S.M., L.C. Sayer, M.A. Milkie and J.P. Robinson, 2012. Housework: Who did, does or will do it and how much does it matter? Soc. Forces, 91: 55-63. DOI: $10.1093 / \mathrm{sf} / \mathrm{sos} 120$

Byron, K., 2005. A meta-analytic review of work-family conflict and its antecedents. J. Vocational Behavior, 67: 169-198. DOI: 10.1016/j.jvb.2004.08.009

Cousins, C.R. and N. Tang, 2004. Working time and work and family conflict in the Netherlands, Sweden and the UK. Work Employment Society, 18: 531-549. DOI: $10.1177 / 0950017004045549$

Crompton, R. and C. Lyonette, 2006. Work-life 'balance' in Europe. Acta Sociol., 49: 379-393. DOI: 10.1177/0001699306071680

den Dulk, L., 2005. Workplace Work-Family Arrangements: A Study and Explanatory Framework of Differences between Organizational Provisions in Different Welfare States. In: Work and Family: An International Research Perspective, Poelmans, S.A.Y. (Ed.), Mahwah, NJ: Lawrence Erlbaum Associates Inc., pp: 211-238.

den Dulk, L., P. Peters and E. Poutsma, 2012. Variations in adoption of workplace work-family arrangements in Europe: the influence of welfare-state regime and organizational characteristics. Int. J. Hum. Resource Manage., 23: 2785-2808.

DOI: $10.1080 / 09585192.2012 .676925$

den Dulk, L., S. Groeneveld, A. Ollier-Malaterre and M. Valcour, 2013. National context in work-life research: A multi-level cross-national analysis of the adoption of workplace work-life arrangements in Europe. Eur. Manage. J., 31: 478-494.

DOI: $10.1016 /$ j.emj.2013.04.010

Eby, L.T., W.J. Casper, A. Lockwood, C. Bordeaux and A. Brinley, 2005. Work and family research in IO/OB: Content analysis and review of the literature (1980-2002). J. Vocational Behavior, 66: 124-197. DOI: $10.1016 /$ j.jvb.2003.11.003
Emrich, C.G., F.L. Denmark and D.N. Den Hartog, 2004. Cross-Cultural Differences in Gender Egalitarianism: Implications for Societies, Organizations and Leaders. In: Culture, Leadership and Organizations: The GLOBE Study of 62 Societies, House, R.J., P.J. Hanges, M. Javidan, P.W. Dorfman and V. Gupta (Eds.), SAGE Publications, Thousand Oaks, ISBN-10: 0761924019, pp: 343-394.

Esping-Andersen, G., 1990. The Three Worlds of Welfare Capitalism. 1st Edn., Princeton University Press, Princeton, ISBN-10: 0691028575, pp: 248.

Esping-Andersen, G., 1999. Social Foundations of Postindustrial Economies. 1st Edn., Oxford University Press, New York, ISBN-10: 0198742002, pp: 207.

Fagnani, J. and M.T. Letablier, 2004. Work and family life balance: The impact of the 35-hour laws in France. Work, Employment Society, 18: 551-572. DOI: $10.1177 / 0950017004045550$

Fenwick, R. and M. Tausig, 1994. The macroeconomic context of job stress. J. Health Soc. Behavior, 35: 266-282.

Figart, D. and E. Mutari, 2000. Work time regimes in Europe: Can flexibility and gender equity coexist? J. Econ. Issu., 34: 847-871.

Frey, B.S. and A. Stutzer, 2002. Happiness and Economics: How the Economy and Institutions Affect Human Well-Being. 1st Edn., Princeton University Press, Princeton, ISBN-10: 0691069980, pp: 220.

Gallie, D., 2003. The quality of working life: Is Scandinavia different? Eur. Sociol. Rev., 19: 61-79. DOI: $10.1093 /$ esr/19.1.61

Galovan, A.M., T. Fackrell, L. Buswell, B.L. Jones and E.J. Hill et al., 2010. The work-family interface in the United States and Singapore: conflict across cultures. J. Family Psychol., 24: 646-656.

Gelfand, M.J., D.P.S. Bhawuk, L.H. Nishii, D.J. Bechtold and L.H. Nishi et al., 2004. Individualism and Collectivism. In: Culture, Leadership and Organizations: The GLOBE Study of 62 Societies, House, R.J., P.J. Hanges, M. Javidan, P.W. Dorfman and V. Gupta (Eds.), SAGE Publications, Thousand Oaks, ISBN-10: 0761924019, pp: 437-512.

Gornick, J.C. and A. Heron, 2006. The regulation of working time as work-family reconciliation policy: Comparing Europe, Japan and the United States. J. Comparative Policy Anal.: Res. Pract., 8: 149-166. DOI: $10.1080 / 13876980600682139$

Gornick, J.C. and M.K. Meyers, 2003. Welfare regimes in relation to paid work and care. Adv. Life Course Res., 8: 45-67. DOI: $10.1016 / \mathrm{S} 1040-2608(03) 08003-1$ 
Greenhaus, J.H. and N.J. Beutell, 1985. Sources of conflict between work and family roles. Acad. Manage. Rev., 10: 76-88.

DOI: $10.5465 / A M R .1985 .4277352$

Grönlund, A. and I. Öun, 2010. Rethinking work-family conflict: Dual-earner policies, role conflict and role expansion in Western Europe. J. Eur. Soc. Policy, 20: 179-195. DOI: $10.1177 / 0958928710364431$

Hakim, C., 2002. Lifestyle preferences as determinants of women's differentiated labor market careers. Work Occupations, 29: 428-459.

DOI: $10.1177 / 0730888402029004003$

Hegewisch, A. and J.C. Gornick, 2011. The impact of work-family policies on women's employment: A review of research from OECD countries. Community, Work Family, 14: 119-138. DOI: $10.1080 / 13668803.2011 .571395$

Hofstede, G., 1980. Culture's Consequences: International Differences in Work-Related Values. 6th Edn., SAGE Publications, Beverly Hills, ISBN-10: 080391444X, pp: 328.

Hofstede, G., G.J. Hofstede and M. Minkov, 2010. Cultures and Organization: Intercultural Corporation and its Importance for Survival. 3rd Edn., McGraw Hill, New York.

Hook, J.L., 2006. Care in Context: Men's Unpaid Work in 20 Countries, 1965-2003. Am. Sociol. Rev., 71: 639-660. DOI: 10.1177/000312240607100406

House, R.J. and M. Javidan, 2004. Overview of the GLOBE Research Program. In: Culture, Leadership and Organizations: The GLOBE Study of 62 Societies, House, R.J., P.J. Hanges, M. Javidan, P.W. Dorfman and V. Gupta (Eds.), SAGE Publications, Thousand Oaks, ISBN-10: 0761924019, pp: 9-28.

House, R.J., P.J. Hanges, M. Javidan, P.W. Dorfman and V. Gupta, 2004. Culture, Leadership and Organizations: The GLOBE Study of 62 Societies. 1st Edn., SAGE Publications, Thousand Oaks, ISBN-10: 0761924019, pp: 818.

Ingram, P. and T. Simons, 1995. Institutional and resource dependence determinants of responsiveness to workfamily issues. Acad. Manage. J., 38: 1466-1482. DOI: $10.2307 / 256866$

Joplin, J.R.W., M.A. Shaffer, A.M. Francesco and T. Lau, 2003. The macro-environment and workfamily conflict: Development of a cross cultural comparative framework. J. Cross Cultural Manage., 3: 305-328. DOI: 10.1177/1470595803003003004

Korpi, W., 2000. Faces of inequality: Gender, class and patterns of inequalities in different types of welfare states. Soc. Politics: Int. Stud. Gender, State Society, 7: 127-191. DOI: $10.1093 / \mathrm{sp} / 7.2 .127$
Lee, S., D. McCann and J.C. Messenger, 2007. Working Time Around the World: Trends in Working Hours, Laws and Policies in a Global Comparative Perspective. 1st Edn., Routledge, ISBN-10: 113407039X, pp: 192.

Lewis, J., 1992. Gender and the development of welfare regimes. J. Eur. Soc. Policy, 2: 159-173. DOI: $10.1177 / 095892879200200301$

Lewis, J., 2009. Work-Family Balance, Gender and Policy. 1st Edn., Edward Elgar Publishing, Cheltenham, ISBN-10: 184844740X, pp: 264.

Lewis, S. and J. Smithson, 2001. Sense of entitlement to support for the reconciliation of employment and family life. Hum. Relations, 54: 1455-1481.

DOI: $10.1177 / 00187267015411003$

Lewis, S. and L. Haas, 2005. Work-Life Integration and Social Policy: A Social Justice Theory and Gender Equity Approach to Work and Family. In: Work and Life Integration: Organizational, Cultural and Individual Perspectives Kossek, E.E. and S.J. Lambert (Eds.), Lawrence Erlbaum Associates, Mahwah, ISBN-10: 0805846166, pp: 349-374.

Lu, L., C.L. Cooper, S.F. Kao, T.T. Chang and T.D Allen et al., 2010. Cross-cultural differences on work-to-family conflict and role satisfaction: A Taiwanese-British Comparison. Hum. Resource Manage., 49: 67-85. DOI: 10.1002/hrm.20334

Lyness, K.S. and M.B. Kropf, 2005. The relationships of national gender equality and organizational support with work-family balance: A study of European managers. Hum. Relations, 58: 33-60. DOI: $10.1177 / 0018726705050934$

Lyness, K.S. and M.K. Judiesch, 2008. Can a manager have a life and a career? International and multisource perspectives on work-life balance and career advancement potential. J. Applied Psychol., 93: 789-805.

Lyness, K.S. and M.K. Judiesch, 2014. Gender egalitarianism and work-life balance for managers: Multisource perspectives in 36 countries. Applied Psychol., 63: 96-129. DOI: 10.1111/apps.12011

Lyness, K.S., J.C. Gornick, P. Stone and A.R. Grotto, 2012. It's all about control: Worker control over schedule and hours in cross-national context. Am. Sociol. Rev., 77: 1023-1049. DOI: $10.1177 / 0003122412465331$

Mandel, H. and M. Semyonov, 2006. A welfare state paradox: State interventions and women's employment opportunities in 22 countries. Am. J. Sociol., 111: 1910-1949. DOI: 10.1086/499912

McCann, D., 2004. Regulating Working Time Needs and Preferences. In: Working Time and Workers' Preferences in Industrialized Countries: Finding the Balance, Messenger, J.C. (Ed.), Routledge, ISBN-10: 1135993327, pp: 10-28. 
McDaniel, A.E., 2008. Measuring gender egalitarianism: The attitudinal difference between men and women. Int. J. Sociol., 38: 58-80. DOI: $10.2753 / \mathrm{IJS} 0020-7659380103$

McGinnity, F. and H. Russell, 2013. Work-Family Conflict and Economic Change. In: Economic Crisis, Quality of Work and Social Integration: The European Experience, Gallie, D. (Ed.), OUP Oxford, Oxford, ISBN-10: 0191641804, pp: 169-194.

Michel, J., L. Kotrba, J.K. Mitchelson, M.A. Clark and B.B. Baltes, 2011. Antecedents of work-family conflict: A meta-analytic review. J. Organizational Behavior, 32: 689-725. DOI: 10.1002/job.695

Mokomane, Z., 2012. Social protection as a mechanism for family protection in sub-Saharan Africa. Int. J. Soc. Welfare.

Nolan, J.P., I.C. Wichert and B.J. Burchell, 2000. Job Insecurity, Psychological Well-Being and Family Life. In: The Insecure Workforce, Heery, E. and J. Salmon (Eds.), Routledge, London, ISBN-10: 0415186714, pp: 181-209.

Ollier-Malaterre, A., M. Valcour, L. den Dulk and E.E. Kossek, 2013. Theorizing national context to develop comparative work-life research: A review and research agenda. Eur. Manage. J., 31: 433-447. DOI: 10.1016/j.emj.2013.05.002

Pettit, B. and J. Hook, 2005. The structure of women's employment in comparative perspective. Soc. Forces, 84: 779-801. DOI: 10.1353/sof.2006.0029

Powell, G.N., A.M. Francesco and Y. Ling, 2009. Toward culture-sensitive theories of the workfamily interface. J. Organizational Behavior, 30: 597-616. DOI: 10.1002/job.568

Ruppanner, L. and M. Huffman, 2013. Blurred boundaries: Gender and work-family interference in cross-national context. Work Occupations, 41: 210236. DOI: $10.1177 / 0730888413500679$

Ruppanner, L., 2011. Conflict between work and family: An investigation of four policy measures. Soc. Indicators Res., 110: 327-347.

DOI: $10.1007 / \mathrm{s} 11205-011-9933-3$

Ruppanner, L.E., 2010. Cross-national reports of housework: An investigation of the gender empowerment measure. Soc. Sci. Res., 39: 963-975. DOI: $10.1016 /$ j.ssresearch.2010.04.002

Sayer, L.C. and J.C. Gornick, 2011. Cross-national variation in the influence of employment hours on child care time. Eur. Sociol. Rev.

DOI: $10.1093 /$ esr/jcr008

Schein, E.H., 1984. Culture as an environmental context for careers. J. Organizational Behavior, 5: 71-81. DOI: $10.1002 /$ job.4030050107

Seeleib-Kaiser, M. and T. Fleckenstein, 2009. The political economy of occupational family policies: Comparing workplaces in Britain and Germany. $\mathrm{Br}$. J. Industrial Relations, 47: 741-764. DOI: $10.1111 /$ j.1467-8543.2009.00741.x
Shaffer, M.A., J.R.W. Joplin and Y.S. Hsu, 2011. Expanding the boundaries of work-family research: A review and agenda for future research. Int. J. Cross Cultural Manage., 11: 221-268. DOI: $10.1177 / 1470595811398800$

Spector, P.E., C.L. Cooper, S. Poelmans, T.D. Allen and M. O'Driscoll et al., 2004. A cross-national comparative study of work-family stressors, working hours and well-being: China and Latin America versus the Anglo world. Personnel Psychol., 57: 119-142.

DOI: $10.1111 /$ j.1744-6570.2004.tb02486.x

Spector, P.E., T.D. Allen, S.A.Y. Poelmans, L.M. Lapierre and C.L. Cooper et al., 2007. Crossnational differences in relationships of work demands, job satisfaction and turnover intentions with work-family conflict. Personnel Psychol., 60: 805-835. DOI: 10.1111/j.1744-6570.2007.00092.x

Steiber, N. and L. Haas, 2012. Advances in explaining women's employment patterns. Socio-Econ. Rev., 10: 343-367. DOI: $10.1093 / \mathrm{ser} / \mathrm{mwr} 039$

Steiber, N., 2009. Reported levels of time-based and strain-based conflict between work and family roles in Europe: A multilevel approach. Soc. Indicators Res., 93: 469-488. DOI: 10.1007/s11205-008-9436-Z

Stier, H. and N. Lewin-Epstein, 2003. Time to work: A comparative analysis of preferences for working hours. Work Occupations, 30: 302-326. DOI: $10.1177 / 0730888403253897$

Stier, H., N. Lewin-Epstein and M. Braun, 2001. Welfare regimes, family-supportive policies and women's employment along the life-course. Am. J. Sociol., 106: 1731-1760. DOI: 10.1086/321302

Strandh, M. and M. Nordenmark, 2006. The interference of paid work with household demands in different social policy contexts: perceived work-household conflict in Sweden, the UK, the Netherlands, Hungary and the Czech Republic. Br. J. Sociol., 57: 597-617. DOI: 10.1111/j.1468-4446.2006.00127.x

Sullivan, O., S. Coltrane, L. McAnnally and E. Altintas, 2009. Father-friendly policies and time-use data in a cross-national context: Potential and prospects for future research. ANNALS Am. Acad. Political Soc. Sci., 624: 234-254. DOI: $10.1177 / 0002716209335138$

Thebaud, S., 2010. Masculinity, bargaining and breadwinning: Understanding men's housework in the cultural context of paid work. Gender Society, 24: 330-354. DOI: 10.1177/0891243210369105

Treas, J. and E. Widmer, 2000. Married women's employment over the life course: Attitudes in crossnational perspective. Soc. Forces, 78: 1409-1436. DOI: $10.1093 / \mathrm{sf} / 78.4 .1409$

Trompenaars, A. and C. Hampden-Turner, 1998. Riding the Waves of Culture: Understanding Cultural Diversity in Global Business. 2nd Edn., McGraw Hill, New York, ISBN-10: 0786311258, pp: 274. 
Uunk, W., M. Kalmijn and R. Muffels, 2005. The impact of young children on women's labour supply: A reassessment of institutional effects in Europe. Acta Sociol., 48: 41-62.

DOI: $10.1177 / 0001699305050986$

Wang, P., J.J. Lawler, F.O. Walumbwa and K. Shi, 2004. Work-family conflict and job withdrawal intentions: The moderating effect of cultural differences. Int. J. Stress Manage., 11: 392-412.

Westman, M., 2005. Cross-Cultural Differences in Crossover Research. In: Work and Family: An International Research Perspective, Poelmans, S.A.Y. (Ed.), Lawrence Erlbaum Associates, Mahwah, ISBN-10: 0805848827, pp: 241-260.
Yang, N., 2005. Individualism-Collectivism in WorkFamily Interfaces: A Sino-US Comparison. In: An International Research Perspective, Poelmans, S.A.Y. (Ed.), Lawrence Erlbaum Associates, Mahwah, ISBN-10: 0805848827, pp: 287-318.

Yang, N., C.C. Chen, J. Choi and Y. Zou, 2000. Sources of work-family conflict: A Sino-U.S. comparison of the effects of work and family demands. Acad. Manage. J., 43: 113-123. DOI: 10.2307/1556390 